\title{
Use of friedewald equation for dyslipidemia in metabolic syndrome
}

\author{
Jaspinder Kaur \\ Medical Officer, Exservicemen Contributory Health Scheme Polyclinic, Sultanpur Lodhi, Kapurthala, Punjab-144626 \\ E-mail: mailtojaspinder@yahoo.in
}

\begin{abstract}
Objective: The Friedewald equation is frequently used to estimate low-density lipoprotein cholesterol (LDL-C) in routine patient care; however, recently many limitations have emerged regarding its use.

Aim: Analyse the use of Friedewald equation for dyslipidemia in metabolic syndrome.

Methods: Subjects were selected with metabolic syndrome that fulfilled consensus statement for Asians Indians and excluded those with triglyceride (TG) $\geq 400 \mathrm{mg} / \mathrm{dl}$, and chronic liver and/or kidney disease. Total cholesterol (TC), high-density lipoprotein cholesterol (HDL$\mathrm{C})$, TGs, and LDL-C were measured with direct assays. LDL-C was further estimated using the equation and compared with LDL-C by direct assay.

Results: The mean and standard deviation of TC, TGs, HDL-C, and LDL-C were $194.77 \pm 24.38 \mathrm{mg} / \mathrm{dl}, 174.84 \pm 60.27 \mathrm{mg} / \mathrm{dl}$ (p<0.0001), $40.68 \pm 5.40 \mathrm{mg} / \mathrm{dl}(\mathrm{p}<0.05)$, and $122.30 \pm 19.30 \mathrm{mg} / \mathrm{dl}$ among subjects with metabolic syndrome. On the other hand, Friedewald estimated LDL-C and VLDL-C were $121.29 \pm 18.84 \mathrm{mg} / \mathrm{dl}$ and $35.08 \pm 12.65 \mathrm{mg} / \mathrm{dl}(\mathrm{p}<0.0001)$. Furthermore, a statistically significant higher TGs/HDL-C $(p<0.0001)$ and LDL-C/HDL-C ratios was observed in subjects with metabolic syndrome. However, no significant difference was recorded between the two methods of estimating LDL-C.

Conclusion: TGs/HDL-C was found significantly higher among subjects with metabolic syndrome; however, no significant difference between both Friedewald equation and direct measurement method for LDL-C estimation was observed. Hence, the accuracy of LDL-C estimation formulas and direct methods for measurement in patients with the metabolic syndrome requires further exploration.
\end{abstract}

Keywords: Dyslipidemia, Friedewald Equation, Metabolic Syndrome.

\section{Introduction}

The metabolic syndrome is a major escalating public-health and clinical challenge worldwide in the wake of urbanization, surplus energy intake, increasing obesity, and sedentary life habits. It represents as a constellation of interconnected physiological, biochemical, clinical, and metabolic risk factors including hypertension, atherogenic dyslipidemia, central obesity, glucose intolerance, pro-inflammatory and pro-thrombotic state which reflects underlying insulin resistance. This atherogenic dyslipidemia is characterized by a spectrum of qualitative lipid abnormalities reflecting perturbations in the structure, metabolism, and biological activities of both atherogenic lipoproteins and antiatherogenic high density lipoprotein cholesterol (HDL-C) which includes an elevation of lipoproteins containing apolipoprotein B (apoB), elevated triglycerides (TGs), increased levels of small particles of low density lipoprotein cholesterol (LDL-C), and low levels of HDL-C (Kaur 2014).

High level of LDL-C is a major risk factor for ischemic heart diseases, and its relation to premature coronary artery disease (CAD) has been demonstrated (Grundy et al. 2004), where each $1 \%$ reduction in LDL can reduce the risk of CAD by $1 \%$ (Robinson et al. 2005). The use of statins in lowering LDL-C is clearly efficacious in the treatment and prevention of CAD. However, despite current therapeutic use of statins as monotherapy even in optimal doses and achieving target LDL-C reduction, a significant number of patients with mixed atherogenic dyslipidemia are at high risk for coronary events (Grundy et al. 2004).

The Friedewald equation which is frequently used to estimate LDL-C in routine patient care; is a central focus of clinical practice guidelines throughout the world, including in the United States (Smith et al. 2011), Europe (Reiner et al. 2011), and Canada (Genest et al. 2009). The Friedewald equation indirectly estimates LDL-C as total cholesterol minus high-density lipoprotein cholesterol minus triglycerides/5 in milligrams per deciliter. The equation introduced into clinical practice in 1972 because the automatic methods are time-consuming and/or require costly equipments and trained personnel (Friedewald et al. 1972). However, the essential limitations are known for the equation which includes hypertriglyceridaemia, type III hyperlipidaemia, low LDL-C concentration and secondary hyperlipidaemias observed in patients with diabetes mellitus, renal disease, hepatic failure, and on hormone replacement therapy (Friedewald et al. 1972, Bairaktari et al. 2004, Jun et al. 2008).

LDL-C should be measured accurately due to its involvement in CAD risk assessment. Otherwise, clinicians will frequently misclassify patients based on National Cholesterol Education Program Adult Treatment Panel III (NCEP ATP III) LDL-C categories when LDL-C is low and triglycerides are elevated using the Friedewald equation to estimate LDL-C. The magnitude of underestimation of LDL-C is often sufficient to lead to under-treatment based on ATP III categorization. However, current guidelines address this issue by recommending non-HDL-C as a secondary 
treatment target when TGs exceed 200mg/dl (2.26mmol/l) (Grundy et al. 2004). Yet, the equation has remained in routine use due to its cost effective nature for the general population with remarkably little scrutiny.

Furthermore, hypertriglyceridemia is considered as an independent predictor of CAD, where the ratio of TG/HDL-C has been proposed as an easily obtainable atherogenic marker (Bittner et al. 2009). The ratio further correlates inversely with the plasma level of small, dense LDL-C particles; where small dense LDL-C particles are more atherogenic than larger buoyant ones. The HDL-C particles correlate inversely with serum TGs and small dense LDL-C; where the larger but less dense HDL-C particles are more protective than the atherogenic small dense HDL-C particles (Da luz et al. 2005).

Hence, the current design is an effort to study lipid panel and ratios in patients with metabolic syndrome so that it can be used as an assessment tool for CAD risk profile in primary care settings and resource poor situations.

\section{Methodology}

A cross-sectional study was designed to analyze the use of Freidewald equation for dyslipidemia in metabolic syndrome. The samples were recruited from ex-servicemen who had been retired from the defense services; their family members comprising spouse, parents and children; both genders aged above 20 years; and those had attended the polyclinic from Aug, 2013 to Sept, 2013. Under the Ex-Servicemen Contributory Health Scheme (ECHS), all registered members are entitled to free at-the-pointof-access medical attention and services from the ECHS polyclinic located at Sultanpur Lodhi, Kapurthala, Punjab (India). Institutional ethical committee approval was obtained prior to the study start, and informed written consent was taken from all the recruited subjects who attended polyclinic during the study period.

\subsection{Definition of metabolic syndrome}

It was defined on the basis of consensus statement for Asians Indians with three out of five variables abnormal for the diagnosis: Obesity $>25.00 \mathrm{~kg} / \mathrm{m}^{2}$, fasting blood glucose $>100 \mathrm{mg} / \mathrm{dl}$ (>5.6mmol/l), hypertension $\geq 130 / \geq 85 \mathrm{mmHg}$, triglycerides(TGs) $>150 \mathrm{mg} / \mathrm{dl}(>1.7 \mathrm{mmol} / \mathrm{l})$ and/or High Density Lipoprotein Cholesterol(HDL-C) $<40 \mathrm{mg} / \mathrm{dl} \quad(<1.03 \mathrm{mmol} / \mathrm{l})$ in men or $<50 \mathrm{mg} / \mathrm{dl}$ $(<1.29 \mathrm{mmol} / \mathrm{l})$ in women. It further includes those previously diagnosed with hypertension, high TGs, low HDL-C, high LDL-C $(>130 \mathrm{mg} / \mathrm{dl} ; 3.36 \mathrm{mmol} / \mathrm{l})$, impaired fasting glucose (IFG), impaired glucose tolerance (IGT) or diabetes mellitus and being on treatment for these disorders (Misra et al. 2009). All subjects were categorized into two groups on the basis of presence or absence of the diagnosis of the metabolic syndrome; however, those with TGs $\geq 400 \mathrm{mg} / \mathrm{dl}(\geq 4.52 \mathrm{mmol} / \mathrm{l})$, and chronic liver and/or kidney disease were excluded.

\subsection{Freidewald equation}

LDL cholesterol $(\mathrm{mg} / \mathrm{dl})=$ Total cholesterol $(\mathrm{mg} / \mathrm{dl})-$ HDL cholesterol (mg/dl) - Triglyceride/5 (mg/dl).

VLDL cholesterol $=$ Triglycerides $/ 5(\mathrm{mg} / \mathrm{dl})$.

\subsection{Clinical measurements}

Participants were weighed to the nearest $0.1 \mathrm{~kg}$ wearing minimal clothes and without shoes; and height was measured to the nearest $0.1 \mathrm{~cm}$ with a wall mounted non-extendable measuring tape. BMI was calculated as weight per square meter $\left(\mathrm{kg} / \mathrm{m}^{2}\right)$. A standard mercury sphygmomanometer with suitable calibrated cuff was used to take blood pressure after subject seated and rested for five minutes.

\subsection{Biochemical analysis}

A venous blood sample was obtained from all the pre-informed individuals after 8-10 hours of fasting. All instruments were checked for calibration before using them to measure blood glucose using Erba glucose kit (GOD-POD method, end point), TC by Erba cholesterol kit (CHOD-PAP method, end point), TGs with Erba triglyceride Des kit (GPO-Trinder method, end point), HDL$\mathrm{C}$ by cholesterol kit (Phosphotungstic acid method, end point), and LDL-C by Erba kit (modified polyvinyl sulfonic acid and polyethylene-glycol methyl ether coupled classic precipitation method).

\subsection{Statistical analysis}

All evaluated variables are presented as means and standard deviation (means \pm SD) using Microsoft Excel 2007. Comparisons between two groups were done by paired t test with statistically significance at $\mathrm{p}<0.05$.

\section{Results}

The present study analyzed total 110 samples; $43.64 \%$ of these were males and $67.36 \%$ were females. The mean age of the study subjects was $58.02 \pm 12.57$ years. The demographic characteristics of the study subjects were further elaborated in Table 1 .

Table 1: Demographic Characteristics of All the Study Subjects (N=110)

\begin{tabular}{lll}
\hline Category & $\begin{array}{l}\text { Number of sub- } \\
\text { jects }\end{array}$ & $\begin{array}{l}\text { Frequency } \\
(\%)\end{array}$ \\
\hline Males & 48 & 43.64 \\
Females & 62 & 67.36 \\
Age & $58.02 \pm 12.57$ & $58.02 \pm 12.57$ \\
Hypertension & 58 & 52.73 \\
Hyperglycemia & 48 & 43.64 \\
Obesity $\left(>25 \mathrm{~kg} / \mathrm{m}^{2}\right)$ & 60 & 54.55 \\
Hypercholesterolemia & 33 & 30.00 \\
Low High Density Lipoprotein- & 37 & 33.64 \\
Cholesterol & & \\
High Low Density Lipoprotein- & 32 & 29.09 \\
Cholesterol & 49 & 44.55 \\
Hypertriglyceridemia & & \\
\hline
\end{tabular}

The study further divided subjects into two groups on the basis of metabolic syndrome: with $(\mathrm{N}=55 ; 50.00 \%)$ and without $(\mathrm{N}=55$; $50.00 \%$ ) the syndrome (Table 2). The mean and standard deviation of TC, TGs and HDL-C were $194.77 \pm 24.38 \mathrm{mg} / \mathrm{dl}$, $174.84 \pm 60.27 \mathrm{mg} / \mathrm{dl}$, and $40.68 \pm 5.40 \mathrm{mg} / \mathrm{dl}$ among subjects with metabolic syndrome; and $192.30 / \mathrm{dl} \pm 26.64,130.02 \pm 26.97 \mathrm{mg} / \mathrm{dl}$, and $43.15 \pm 7.06 \mathrm{mg} / \mathrm{dl}$ were the values for the same variables among subjects without metabolic syndrome, respectively. It shows statistically significant higher ranges of TGs $(p<0.0001)$, HDL-C ( $\mathrm{p}<0.05)$, and TC in subjects with the diagnosis of metabolic syndrome than without it.

Table 2: Comparison of Lipid Panel in Subjects With and Without Metabolic Syndrome

\begin{tabular}{|c|c|c|c|}
\hline \multirow{2}{*}{ Category } & \multicolumn{2}{|c|}{ Metabolic Syndrome } & \multirow{2}{*}{$P$ value } \\
\hline & Yes (55) & No $(55)$ & \\
\hline Total Cholesterol & $194.77 \pm 24.38$ & $192.30 \pm 26.64$ & 0.614 \\
\hline Triglycerides & $174.84 \pm 60.27$ & $130.02 \pm 26.97$ & $<0.0001$ \\
\hline $\begin{array}{l}\text { High Density Lipoprotein- } \\
\text { Cholesterol }\end{array}$ & $40.68 \pm 5.40$ & $43.15 \pm 7.06$ & $<0.05$ \\
\hline $\begin{array}{l}\text { Low Density Lipoprotein- } \\
\text { Cholesterol (calculated) }\end{array}$ & $121.29 \pm 18.84$ & $122.60 \pm 22.34$ & 0.740 \\
\hline $\begin{array}{l}\text { Low Density Lipoprotein- } \\
\text { Cholesterol (measured) }\end{array}$ & $122.30 \pm 19.30$ & $123.70 \pm 23.34$ & 0.7324 \\
\hline $\begin{array}{l}\text { Very Low Density Lipopro- } \\
\text { tein- Cholesterol }\end{array}$ & $35.08 \pm 12.65$ & $26.00 \pm 5.40$ & $<0.0001$ \\
\hline
\end{tabular}

Further, the Friedewald calculated LDL-C were $121.29 \pm 18.84 \mathrm{mg} / \mathrm{dl}$ and direct measured LDL-C were $122.30 \pm 19.30 \mathrm{mg} / \mathrm{dl}$ among subjects with metabolic syndrome. This shows no significant differences between two methods of direct measurement and Friedewald estimation for LDL-C with mean difference of $1.01 \mathrm{mg} / \mathrm{dl}$, correlation coefficient of 0.0354 , 
and $\mathrm{p}$ value of 0.714 . Contrarily, the Friedewald calculated VLDL-C were $35.08 \pm 12.65 \mathrm{mg} / \mathrm{dl}$ and $26.00 \pm 5.40 \mathrm{mg} / \mathrm{dl}$ in both groups; which shows statistically significant $(\mathrm{p}<0.0001)$ higher ranges in subjects with metabolic syndrome $(35.08 \pm 12.65 \mathrm{mg} / \mathrm{dl})$ as compared to individuals with no syndrome $(26.00 \pm 5.40 \mathrm{mg} / \mathrm{dl})$. Figure 1 represents the graphical correlation of Friedewald estimated LDL-C levels in subjects with and without metabolic syndrome.

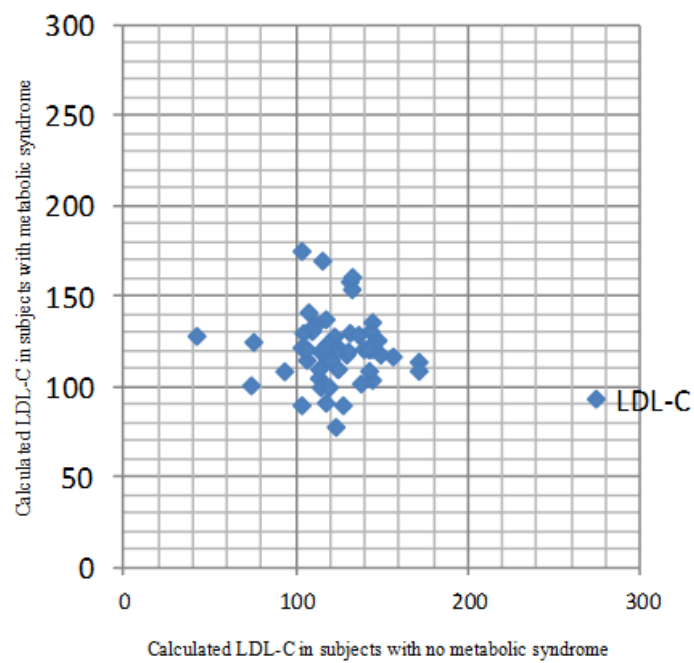

Fig.1. Graphical correlation of calculated LDL in subjects with and without metabolic syndrome

Table 3 reveals the lipid ratios in all the study subjects. The calculated mean and standard deviation of TG/HDL-C, TC/HDL-C, and LDL-C/HDL-C ratios were $4.35 \pm 1.53,4.86 \pm 0.75$, and $3.03 \pm 0.61$ for subjects with metabolic syndrome; and 3.08 $\pm 0.76,5.21 \pm 5.11$, and $2.91 \pm 0.68$ were calculated for the same ratios among subjects with no metabolic syndrome. It further reveals a statistically significant higher TG/HDL-C $(\mathrm{p}<0.0001)$ and LDL-C/HDL-C ratios in subjects diagnosed with metabolic syndrome, with no significant difference between TC/HDL-C ratios in both groups.

Table 3: Comparison of Lipid Ratios in Subjects With and Without Metabolic Syndrome

\begin{tabular}{llll}
\hline \multirow{2}{*}{ Category } & \multicolumn{2}{l}{ Metabolic Syndrome } & \multirow{2}{*}{ P value } \\
& Yes (55) & No (55) & \\
\hline TGs/HDL-C & $4.35 \pm 1.53$ & $3.08 \pm 0.76$ & $<\mathbf{0 0 0 1}$ \\
TC/HDL-C & $4.86 \pm 0.75$ & $5.21 \pm 5.11$ & 0.6163 \\
LDL-C/HDL-C & $3.03 \pm 0.61$ & $2.91 \pm 0.68$ & 0.3321 \\
\hline
\end{tabular}

TGs: Triglycerides, HDL-C: High Density Lipoprotein- Cholesterol, TC:

Total Cholesterol, LDL-C: Low Density Lipoprotein- Cholesterol.

\section{Discussion}

The current study (Table 2) noticed no significant differences among the LDL-C values measured by Friedewald equation $(121.29 \pm 18.84 \mathrm{mg} / \mathrm{dl})$ and direct method $(122.30 \pm 19.30 \mathrm{mg} / \mathrm{dl})$. Similarly, Knopfholz et al. (2014) found that Friedewald formula is a good method for estimating LDL-C in patients with metabolic syndrome. Furthermore, Sahu et al. (2005) reported that the use of Friedewald formula is a cost saving and reliable estimate of LDL$\mathrm{C}$ when HDL-C and TC were determined.

However, Martin et al. (2013) observed that Friedewald equation tends to underestimate LDL-C in the setting of high TG levels, especially at low LDL-C levels, which could result in under treatment of high-risk patients, and further suggested additional evaluation, especially if TGs are $\geq 150 \mathrm{mg} / \mathrm{dl}(>1.7 \mathrm{mmol} / \mathrm{l})$. Similarly, Charuruks \& Milintagas (2005) indicated the direct measurement of LDL-C when TG $\geq 200 \mathrm{mg} / \mathrm{dl}(2.26 \mathrm{mmol} / \mathrm{l})$ because they found that the direct method was more precise and accurate than Friedewald equation, even for TG levels between 200 and 399 $\mathrm{mg} / \mathrm{dl}(2.26-4.49 \mathrm{mmol} / \mathrm{l})$. On the other hand, Piva \& Fernandes (2008) observed that Friedewald formula tends to significantly overestimates LDL-C values when compared to direct measurement methods.

Moreover, some studies have shown that Friedewald equation can also display discrepancies in low TG values (Sahu et al. 2005, Piva \& Fernandes 2008). When TG was $<70 \mathrm{mg} / \mathrm{dl}(0.8 \mathrm{mmol} / \mathrm{l})$, the estimated LDL-C using the Friedewald equation showed slightly lower values than that using the direct method (Piva \& Fernandes 2008). Contradictory results have been demonstrated by Sahu et al. (2005), in which serum LDL-C using the Friedewald formula was higher than the homogeneous assay for TG $<100$ or $200 \mathrm{mg} / \mathrm{dl}(1.12$ or $2.26 \mathrm{mmol} / \mathrm{l})$.

This shows the controversy exist between studies in comparing direct method with Friedewald formula. Various reasons for these differences might be in regard to other serum lipid levels, especially TGs; the influence of fasting and non-fasting samples on lipid measurement; and biochemical tests quality control in each laboratory. Moreover, it has been suggested that Friedewald formula is required to define the lipid phenotype (Yu et al. 2000).

Furthermore, Puavilai et al. (2009) found more accuracy in the new modified Friedewald equation, which is LDL =TC-HDL1/6TG, to calculate serum LDL-C level from non-fasting TG levels, regardless of the time of last meal if serum TGs $<300 \mathrm{mg} / \mathrm{dl}$ $(3.39 \mathrm{mmol} / \mathrm{l})$. Diabetes is the epitome of metabolic syndrome; however, new studies are demonstrating the limited efficacy of Friedewald formulae in diabetic patients. In diabetic patients, with or without insulin use, the Friedewald equation on average underestimates $8 \%$ serum LDL-C, but it can underestimate more than $10 \%$ in patients with TG levels between 200 and $400 \mathrm{mg} / \mathrm{dl}(2.26-$ 4.5mmol/l) (Hirany et al. 1997). Conversely, Whiting et al. (1997) observed that the Friedewald formula provide an accurate estimation of LDL-C among diabetic patients with plasma TGs $<400 \mathrm{mg} / \mathrm{dl}(<4.5 \mathrm{mmol} / 1)$; and further suggested that the direct immunoseparation method significantly overestimated LDL-C at TGs between 178 and $400 \mathrm{mg} / \mathrm{dl}(2-4.5 \mathrm{mmol} / 1)$.

The study further reveals a statistically significant higher TG/HDL-C $\quad(4.35 \pm 1.53 ; \quad \mathrm{p}<0.0001)$ and LDL-C/HDL-C $(3.03 \pm 0.61)$ ratios in subjects diagnosed with metabolic syndrome (Table 3). TG/HDL-C ratio especially more than four (Da luz et al. 2005) is a powerful predictor of total mortality independent of important prognostic variables including age, race, smoking, hypertension, diabetes, and severity of coronary artery disease; even stronger than TC/HDL-C and LDL-C/HDL-C (Bittner et al. 2009). The Copenhagen Male Study showed triglycerides on their own to be another strong risk factor, but found that stratifying TGs levels by HDL-C levels led to more accurate detection of increased coronary disease risk (Jespersen et al. 1998). The atherogenic link between high TGs and low HDL-C is due to the higher plasma concentration of TG-rich, very low-density lipoprotein that generates small, dense LDL during lipid exchange and lipolysis. These LDL particles accumulate in the circulation and form small, dense HDL particles, which undergo accelerated catabolism, thus closing the atherogenic circle (Da Luz et al. 2008). Thus, this ratio is an easy, non-invasive means of predicting the presence and extent of coronary atherosclerosis.

Limitation: The present study did not take into account the current use of medication or the inflammatory state of the patients. Since the commonly used statin, angiotensin converting enzyme inhibitors and angiotensin II receptor blockers may alter the inflammatory state, and may weaken the relationship between TC and LDL$\mathrm{C}$ due to their action more on LDL-C and less on HDL-C and TGs However, more studies using larger samples taken from different ethnic and geographic populations and preferably compared with reference method of ultracentrifugation and precipitation would further accomplish this work. Additionally, considering the different ranges of TGs will certainly give more information about the degree of inaccuracy of Friedewald equation. 


\section{Conclusion}

TGs/HDL-C was found significantly higher among subjects with metabolic syndrome; however, no significant difference between both Friedewald equation and direct measurement method for LDL-C estimation was observed. Subsequent research including $\beta$-quantification by ultracentrifugation validation is required in order to explore the accuracy of LDL-C estimation formulas and direct methods in patients with the metabolic syndrome who exhibit abnormal abundance of small dense LDL-C particles. Hence, LDL-C estimation warrants consideration in contemporary patient care, as clinicians care for patients, as experts formulate clinical practice guidelines, and as investigators design future research studies.

\section{Acknowledgment}

I acknowledge all the patients who gave their permission to be a part of this study and thankful to the entire staff of polyclinic for their consistent support and Ms. Manjit Kaur for her assistance in the statistical analysis.

\section{References}

[1] Bairaktari ET, Tzallas C, Kalientzidou M, Tselepis AD, Siamopoulos KC, Seferiadis KI \& Elisaf M (2004) Evaluation of alternative calculation methods for determining low-density lipoprotein cholesterol in hemodialysis patients. Clinical Biochemistry 37, 937-940.

[2] Bittner V, Johnson BD, Zineh I, Rogers WJ, Vido D, Marroquin OC, Bairey-Merz CN \& Sopko G (2009) The TG/HDL Cholesterol Ratio Predicts All-Cause Mortality in Women With Suspected Myocardial Ischemia A Report from the Women's Ischemia Syndrome Evaluation (WISE). American Heart Journal 157, 548-555.

[3] Charuruks N \& Milintagas A (2005) Evaluation of calculated low density lipoprotein against a direct assay. Journal of the Medical Association of Thailand 88, S274-S279.

[4] Da luz PL, Cesena FH, Favarato D \& Cerqueira ES (2005) Comparison of serum lipid values in patients with coronary artery disease at $<50,50$ to 59,60 to 69 , and $>70$ years of age. American Journal of Cardiology 96, 1640-3.

[5] Friedewald WT, Levy RI \& Fredrickson DS (1972) Estimation of the concentration of low-density lipoprotein cholesterol in plasma, without use of the preparative ultracentrifuge. Clinical Chemistry 18, 499502.

[6] Genest J, McPherson R, Frohlich J, Anderson T, Campbell N, Carpentier A, Couture P, Dufour R, Fodor G, Francis GA, Grover S, Gupta M, Hegele RA, Lau DC, Leiter L, Lewis GF, Lonn E, Mancini GBJ, Ng D, Pearson GJ, Sniderman A, Stone JA \& Ehud Ur (2009) Canadian guidelines for the diagnosis and treatment of dyslipidemia and prevention of cardiovascular disease in the adult. Canadian Journal of Cardiology 25, 567-79.

[7] Grundy SM, Cleeman JI, Merz CN, Brewer HB Jr., Clark LT Hunninghake DB Pasternak RC, Smith SC Jr, \& Stone NJ (2004) National Heart, Lung, and Blood Institute; American College of Cardiology Foundation; American Heart Association. Implications of recen clinical trials for the national cholesterol education program adult Treatment Panel III guidelines. Circulation 110, 227-39.

[8] Hirany S, Li D \& Jialal I (1997) A more valid measurement of lowdensity lipoprotein cholesterol in diabetic patients. The American Journal of Medicine 102, 48-53.

[9] Jeppesen J, Hein HO, Suadicani P \& Gyntelberg F (1998) Triglycerides concentration and ischemic heart disease: an eight-year follow-up in the Copenhagen Male Study. Circulation 97, 1029-36.

[10]Jun KR, Park HI, Chun S, Park H \& Min WK (2008) Effects of total cholesterol and triglyceride on the percentage difference between the LDL-C concentrations measured directly and calculated using the Friedewald formula. Clinical Chemistry and Laboratory Medicine 46, 371-5.

[11]Kaur J (2014) A comprehensive review of metabolic syndrome. Cardiology Research and Practice Article ID 943162, 1-21.

[12]Knopfholz J, Disserol CCD, Pierin AJ, Schirr FL, Streisky L, Takito LL, Ledesma PM, Faria-Neto JR, Olandoski M, Cunha CLPD \& Bandeira AM (2014) Validation of the Friedewald Formula in Patients with Metabolic Syndrome. Cholesterol Article ID 261878, 1-5.
[13]Luz PLD, Favarato ID, Faria-Neto IJR Jr., Lemos P \& Chagas IACP (2008) High ratio of triglycerides to hdl-cholesterol predicts extensive coronary disease. Clinics 64, 427-32.

[14]Martin SS, Blaha MJ, Elshazly MB, Brinton EA, Toth PP, McEvoy JW, Joshi PH, Kulkarni KR, Mize PD, Kwiterovich PO, DeFilippis AP, Blumenthal RS \& Jones SR (2013) Friedewald-Estimated Versus Directly Measured Low-Density Lipoprotein Cholesterol and Treatment Implications. Journal of the American College of Cardiology 62, 732-9.

[15]Misra A, Chowbey P, Makkar BM, Vikram NK, Wasir JS, Chadha D, Joshi SR, Sadikot S, Gupta R, Gulati S, Munjal YP \& Concensus Group (2009) Consensus statement for diagnosis of obesity, abdominal obesity and the Metabolic Syndrome for Asian Indians and Recommendations for Physical activity, medical and surgical management. Journal of Association of Physicians of India 57, 163-170.

[16]Piva JPJ \& Fernandes TRL (2008) Comparac, ao anal'itica de valores de LDL-colesterol utilizando a dosagem direta e o c'alculo pela f'ormula de Friedewald. Revista Brasileira de An'alises Cl'inicas 40, 279-283.

[17] Puavilai W, Laorugpongse D, Deerochanawong C, Muthapongthavorn N \& Srilert P (2009) The Accuracy in Using Modified Friedewald Equation to Calculate LDL from Non-Fast Triglyceride: A Pilot Study. Journal of the Medical Association of Thailand 92, 182-7.

[18]Reiner Z, Catapano AL, De Backer G, Graham I, Taskinen MR, Wiklund O, Agewall S, Alegria E, Chapman MJ, Durrington P, Erdine S, Halcox J, Hobbs R, Kjekshus J, Filardi PP, Riccardi G, Storey RF, Wood D, Bax J, Vahanian A, Auricchio A, et al. (2011) ESC/EAS guidelines for the management of dyslipidaemias: The Task Force for the management of dyslipidaemias of the European Society of Cardiology (ESC) and the European Atherosclerosis Society (EAS). European Heart Journal 32, 1769-818.

[19]Robinson JG, Smith B, Maheshwari N \& Schrott H (2005) Pleiotropic effects of statins: Benefit beyond cholesterol reduction? A metaregression analysis. Journal of the American college of cardiology 46, 1855-62.

[20]Sahu S, Chawla R \& Uppal B (2005) Comparison of two methods of estimation of low density lipoprotein cholesterol, the direct versus friedewald estimation. Indian Journal of Clinical Biochemistry 20, 5461.

[21]Smith SC Jr., Benjamin EJ, Bonow RO, Braun LT, Creager MA, Franklin BA, Gibbons RJ, Grundy SM, Hiratzka LF, Jones DW, Lloyd-Jones DM, Minissian M, Mosca L, Peterson ED, Sacco RL, Spertus J, Stein JH \& Taubert KA (2011) AHA/ACCF secondary prevention and risk reduction therapy for patients with coronary and other atherosclerotic vascular disease: 2011 update. Journal of the American college of cardiology 58, 2432-46.

[22]Whiting MJ, Shephard MDS \& Tallis GA (1997) Measurement of Plasma LDL Cholesterol in Patients with Diabetes. Diabetes Care 20, 12-14.

[23] Yu HH, Markowitz R, De Ferranti SD, Neufeld EJ, Farrow G, Bernstein HH \& Rifai N (2000) Direct measurement of LDL-C in children: Performance of two surfactant-based methods in a general pediatric population. Clinical Biochemistry 33, 89-95. 